\title{
Green Office Concept Assessment Study In The Council Show The Office Care
}

\author{
Endang Supriyadi a,1,*, Maya Sofiana ${ }^{\text {b,2, }}$, Rita Wahyuni ${ }^{b, 3}$ \\ ${ }^{\text {a }}$ Institut Ilmu Sosial dan Manajemen Stiami \\ ${ }^{\mathrm{b}}$ Institut Ilmu Sosial dan Manajemen Stiami \\ ${ }^{1}$ maya72sofiana@gmail.com* \\ * corresponding author
}

\section{ARTICLE INFO}

\section{Article History}

Received Desember 2019

Revised Januari 2020

Accepted Februari 2020

Keywords

Concept of Green Office,

Office Care

\begin{abstract}
One of the global problems that is currently happening is increasingly serious environmental damage. Offices from companies/organizations have a major contribution to environmental damage. Various calmities that occur at this time, are not accidental, Fire, landslides, and floods are indications of environmental damage. With these conditions various efforts by the green movement were made to create environmentally friendly offices. From the top level to the bottom, companies/organizations must caretop level to the bottom, companies / organizations must care and participate with the environment. Participating in realizing office buildings that are environmentally friendly is not necessary with activities that require large amounts of energy, time and cost, but enough for activities that we consider small but have a big impact on saving the environment are very meaningful, such as energy efficiency (saving electricity and water) and greening including. The purpose of this paper is to describe the alternative strategic steps taken to achieve the concept of green office to create environmentally friendly offices.

The writing method used is the research methodology used in this study using descriptive research methodology or literature review. The results showed that there were company committed to implementing a green office including PT Mandiri (Persero) Tbk., Surakarta in Central Java
\end{abstract}

\section{PENDAHULUAN}

Salah satu permasalahan global yang saat ini terjadi adalah kerusakan lingkungan yang semakin serius. Perkantoran dari perusahaan/organisasi mempunyai kontribusi besar terhadap kerusakan lingkungan. Berbagai musibah yang terjadi saat ini, bukanlah kebetulan. Musibah kebakaran, tanah longsor dan banjir merupakan salah satu indikasi kerusakan lingkungan. Dengan adanya kondisi tersebut maka berbagai upaya gerakan hijau pun dilakukan untuk mewujudkan perkantoran yang ramah lingkungan. Dari level teratas sampai dengan terbawah perusahaan/organisasi harus perduli dan berpartisipasi dengan lingkungan. Berpartisipasi dalam mewujudkan perkantoran yang ramah lingkungan tidak perlu dengan kegiatan yang memerlukan tenaga, waktu dan biaya yang besar tetapi cukup dengan kegiatan yang kita anggap kecil tetapi berdampak besar perannya dalam penyelamatan lingkungan sangat berarti, seperti efisiensi energy (penghematan listrik dan air) dan peghijauan diantaranya.

Kerusakan lingkungan yang masif ini disebabkan oleh eksplotasi besar-besaran oleh manusia sebagai pelaku usaha dalam binis secara tidak bertanggung jawab dengan pertumbuhan perkantoran yang tidak perduli dengan aspek keselamatan lingkungan. Persaingan antar bisnis yang sangat kompetitif dengan lingkup tanpa batas dan perkembangan teknologi yang begitu pesat menyebabkan penggunaan energi, sumberbdaya alam dan limbah berbahaya menyebabkan kerusakan lingkungan baik secara kualitas dan kuantitas.

Berbagai bencana diantaranya kebakaran, banjir, tanah longsor marak terjadi 5 tahun terakhir ini salah satunya disebabkan oleh perkantoran yang pertumbuhannya berkembang pesat tanpa dibarengi dengan gerakan kepedulian menjaga lingkungan, sehingga kualitas lingkungan hidup semakin lama semakin menurun. Badan Pusat Statistik (BPS) telah melakukan Sensus Ekonomi 2016. Dari hasil sensus, jumlah perusahaan di Indonesia tercatat ada sebanyak 26,7 juta. Angka ini meningkat dibanding 
hasil Sensus Ekonomi 2006 yang sebanyak 22,7 juta perusahaan. Artinya, ada 3,98 juta perusahaan baru dalam 10 tahun terakhir. (Detik Kamis, 27 Apr 2017 14:14 WIB.).

Maraknya pertumbuhan perkantoran ini dapat dilihat Jumlah Perusahaan di Indonesia dalam hal ini dapat dikategorikan dalam Usaha Menengah Kecil (UMK) dan Usaha Menengah Besar (UMB) dari data Badan Pusat Statistik (BPS) pada Sensus Ekonomi 2016 berikut ini:

\section{Gambar 1}

\section{Jumlah Perusahaan di Indonesia}

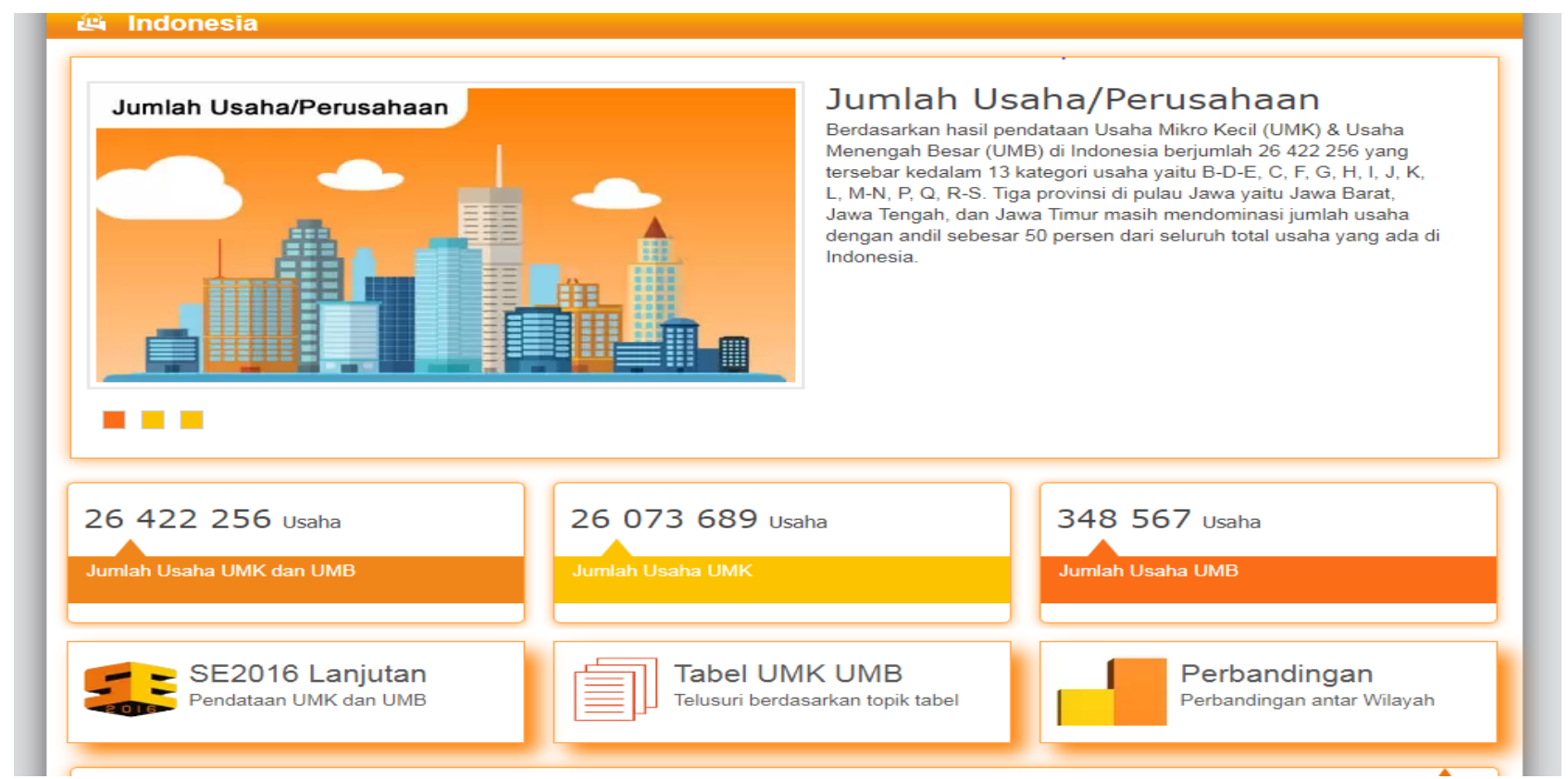

\section{Sumber : BPS Sensus Ekonomi 2016}

Jumlah perusahaan di Indonesia tersebar di seluruh pulau di Indonesia hal ini berdampak pada kerusakan lingkungan yang sangat luas tidak hanya terjadi di pulau Jawa . Bencana terjadi di manamana akibat dari keegoisan manuasia yang mengeksploitasi besar-besaran sumber energi, sumberdaya alam dan dihasilkannya limbah berbahaya dalam jumlah besar. Persebaran jumlah perusahaan dalam hal ini UMK dan UMB paling besar di pulau Jawa. Hal ini berdampak pada penurunan kualitas dan kuantitas lingkungan terbesar di pulau Jawa. Seperti tabel di bawah ini. Dilihat dari persebaran antar pulau, pulau Jawa Menempati posisi pertama dan Sumatera posisi kedua, posisi menempati posisi terakhir ada Maluku dan Papua. Dapat dikatakan maka kerusakan akan terjadi dalam jangkauan terluas di pula Jawa, mengikuti di posisi selanjutnya adalah pulau-pulau yang lain seperti terlihat di tabel bawah ini:

Tabel 1

Persebaran Jumlah Perusahaan di Indonesia

\begin{tabular}{|c|c|c|c|c|}
\hline Pulau & UМк & UMB & Jumlah & $\begin{array}{c}\text { Distribusi } \\
(\%)\end{array}$ \\
\hline (1) & (2) & (3) & (4) & (5) \\
\hline Sumatera & 4.897 .457 & 74.276 & 4.971 .733 & 18,61 \\
\hline Jawa & 15.931 .889 & 291.697 & 16.223 .586 & 60,74 \\
\hline Bali dan Nusa Tenggara & 1.495 .526 & 22.088 & 1.517 .614 & 5,68 \\
\hline Kalimantan & 1.352 .324 & 26.645 & 1.378 .969 & 5,16 \\
\hline Sulawesi & 2.134 .579 & 25.110 & 2.159 .689 & 8,09 \\
\hline Maluku dan Papua & 451.874 & 7.536 & 459.410 & 1,72 \\
\hline Jumlah & $\begin{array}{r}26.263 .649 \\
(98,33)\end{array}$ & $\begin{array}{r}447.352 \\
(1,67)\end{array}$ & $\begin{array}{r}26.711 .001 \\
(100,00)\end{array}$ & 100,00 \\
\hline
\end{tabular}


Kerusakan lingkungan yang marak di Indonesia diantaranya pencemaran laut yaitu limbah domestik mencapai $75 \%$, limbah perkantoran dan daerah komersial mencapai $15 \%$ dan limbah industry mencapai $10 \%$. Sedangkan, penyebab pencemaran laut yaitu limbah industri, pengecatan kapal, reklamasi, limbah rumah tangga, kegiatan pelabuhan dan pelayaran. Setidaknya ada 10 permasalahan lingkungan di Indonesia yaitu sampah, banjir, pencemaran sungai, rusaknya ekosistem laut, pemanasan global, pencemaran udara, sulitnya air bersih, kerusakan hutan, abrasi dan pencemaran tanah. (Jurnal Intelejen.Net) Semestinya besar atau kecil dan apapun bentuk usahanya seharusnya pelaku usaha berkomitmen dengan kualitas lingkungan hidup.. Seiring dengan pertumbuhan perusahaan sejalan juga dengan komitmen pada kualitas dan kualitas lingkungan hidup. Meningat dampak dari aktivitas kantor yang berdampak pada kerusakan lingkungan maka pemerintah melindungi lingkungan dengan mengeluarkan Undang-Undang Nomor 32 Tahun 2009 tentang Perlindungan dan Pengelolaan Lingkungan hidup yang menekankan pentingnya peran pemerintah dalam mendorong dan memfasilitasi prakarsa para pemangku kepentingan dalam melaksanakan upaya mitigasi dan adaptasi terhadap perubahan iklim melalui pengelolaan bangunan ramah lingkungan.

Hal ini dapat dibangun dengan adanya perilak untuk perduli dan komitmen dengan lingkungan dimulai dari perilaku indvidu atau masyarakat sebagai pelaku usaha. Namun karena perilaku manusia yang egois menyebabkan kerusakan masif. Mengingat begitu banyak pekerjaan rumah terkait dengan kerusakan lingkungan di Indonesia sehingga peneliti tertarik untuk meneliti Kajian Penerapan Konsep Green Office dalam Rangka Menwujudkan Perkantoran Ramah Lingkungan.

\section{KAJIAN PUSTAKA}

\section{Green Office}

Sebelum membahas mengenai penelitian ini perlu diketahui terlebih dulu konsep Green Office. Yang mana Green Office merupakan proses pengelolaan kantor yang efisien dalam hal penggunaan sumber daya dan berkomitmen lingkungan. Sesuai dengan pedoman kantor hijau dan sehat Kementerian Kesehatan R1 Green Office atau Kantor Hijau adalah kantor yang struktur dan proses pengelolaanya efisien dalam menggunakan sumber daya dan berwawasan lingkungan sepanjang siklus hidupnya di.mulai dari penentuan lokasi, desain dan kontribusi gedung kantor, kegiatan operasional, pemeliharaan dan renovasi yang diselenggarakan didalamnya, hingga perilaku penggunanya sehingga tujuan Kantor Hijau dapat terwujud (Simanjuntak dkk., 2015: 3). dalam Fitriani \& Astuti (2016:65).

Untuk efektifitas penerapan green office, maka perlu diadakan penilaian kinerja green office. Mengadopsi dengan kantor pemerintah Penilaian kinerja green office telah dimulai sejak tahun 2012 hingga saat ini, aspek yang dinilai antara lain hemat energy, yakni: listrik dan BBM, penyehatan air, hygiene dan sanitasi, lahan dan penghijauan, serta kualitas udara dalam ruang.Mufidah (2017:29). Sementara itu menurut Artur Provodor (20 l 0 ) dalam Fitriani \& Astuti (2016:65) menyebutkan beberapa indikator kinerja lingkungan pada konsep green office sebagai berikut :

1) Lokasi dan struktural Desain Efisiensi (Sitting and Structural Design Efficiency); pertimbangan semua tahapan siklus hidup dari proyek pembangunan pada tahap konsep dan desain

2) Efisiensi Energi (Energy Efficiency); mempertimbangkan pengguna energi dalam pembangunan dan penggunaan bangunan; rasio penggunaan sumber energi alami terhadap total energi yang digunakan oleh bangunan; investasi yang dilakukan dalam perbaikan dalarn efisiensi energi.

3) Efisiensi air (Water Efficiency); mempertimbangkan penggunaan air melalui rasio kepemilikan tempat dan/atau pemurnian air dengan total konsumsi air (air yang dipasok dari akuifer alami)

4) Efisiensi bahan (Materials Efficiency); mempertimbangkan rasio bahan/material "hijau", daur ulang barang-barang industri dan/atau pemanfaat bahan daur ulang.

5) Upaya kualitas lingkungan ruang kantor (Indoor Environmental Quality Enhancement); mempertimbangkan kualitas udara dalam ruangan, kualitas termal (suhu) dan kualitas pencahayaan.

6) Optirnalisasi Operasional dan Perneliharaan (Operations and Maintenance Optimisation O\&M); keterlibatan staf di semua tahapan kegiatan rarnah lingkungan. 
7) Pengurangan Lirnbah dan Toxics (Waste and Toxics); Mempertimbangkan penyediaan peralatan, seperti tempat sampah kompos, untuk mengurangi bahan organik akan ke tempat pembuangan sampah; pengenalan praktek daur ulang, konversi lirnbah dan air limbah menjadi pupuk.

Green office ini dalam implementasinya agar optimal maka harus tercermin dalam kebijakan kantor. Seperti pendapat Sugiarto dan Dewi (2016) dalam Rahmawati (2017:128) Green office merupakan refleksi kebijaksanaan kantor yang menerapkan sistem manajemen lingkungan (SML) dalam upaya menciptakan lingkungan kerja kantor bersih, indah dan nyaman serta menyehatkan dan tidak menggangu lingkungan sekitar. Dengan adanya kebijakan dalam penerapan konsep green office maka perilaku individu diarahkan menjadi peduli dan berkomitmen dalam menciptakan kantor yang ramah lingkungan diharapkan akan mengkristal ke dalam budaya kerja. Beberapa praktik sederhana yang dapat diterapkan untuk mulai melakukan inisiasi pendekatan kantor ramah lingkungan dapat dilakukan dengan cara hemat kertas, hemat air; hemat energi, daur ulang, transportasi bersama, catridge tinta, hijaukan ruang kerja, dan bawa makan siang dari rumah. Fitriani dan Astuti (2016:66)

\section{Ramah Lingkungan}

Dengan adanya kerusakan lingkungan maka gerakan ramah lingkungan mulai digalakkan. Adapun istilah Ramah lingkungan adalah tidak merusak lingkungan, melainkan menjaga dan melestarikan lingkungann tempat dimana umat manusia melangsungkan kehidupan.Amalia dan Sarwono (2010:480)

\section{ISO 14001}

Untuk mewujudkan optimalisasi green office diperlukan suatu ukuran baku untuk mengukur kinerja green office. Standar internasional ISO 14000 adalah sistem manajemen lingkungan (Environmental Management Sistem) yang mengntegrasikan tanggung jawab lingkungan kedalam manajemen sehari-hari perusahaan. Pendekatan bersifat sukarela, perbaikan terus-menerus dan diperkirakan akan menjadi paspor internasional untuk perusahaan-perusahaan yang melakukan bisnis dengan negara-negara yang dengan kepeduliaannya terhadap lingkungan sudah tinggi (Sutrisno, 1996) dalam Maninriang (2013:33)

\section{METODE PENELITIAN}

Metodologi penelitian yang digunakan pada penelitian ini menggunakan metodologi penelitian deskriptif atau kajian pustaka. Adapun metode penelitian kajian pustaka atau studi kepustakaan yaitu berisi teori teori yang relevan dengan masalah-masalah penelitian. Menurut Sujarweni (2014:57). Kajian pustaka berfungsi untuk membangun konsep atau teori yang menjadi dasar studi dalam penelitian. Dalam rangka mengembangkan aspek teoritis dan praktis dalam penelitian akademik maka penelitian studi pustaka wajib dilakukan Seperti pendapat Sukardi (2013:33) kajian pustaka atau studi pustaka merupakan kegiatan yang diwajibkan dalam penelitian,khususnya penelitian akademik yang tujuan utamanya adalah mengembangkan aspek teoritis maupun aspek manfaat praktis.

\section{HASIL PENELITIAN}

Adapun hasil penelitian ini didapat dari kajian pustaka dari beberapa hasil penelitian beberapa peneliti yakni:

a. Implementasi konsep Green Office di lingkungan gedung Bank Mandiri dilakukan oleh Rukmita dkk (2018: 372-376) berjudul Implementasi Konsep Green Office Berdasarkan Perilaku Pengguna Di Lingkungan Gedung hasil penelitian penerapan green office berfokus pada pengamatan 5 aspek yaitu diataranya :

\section{1) Aspek Penghematan Listrik}

Yaitu upaya yang dilakukan untuk menggunakan listrik secukupnya, hal ini dapat dilihat dari penggunaan lampu, penggunaan $\mathrm{AC}$, penggunaan komputer dan sosialisasi penghematan litsrik berdasakan perilaku pengguna gedung yaitu baik pegawai maupun pelanggan. pendingin ruangan) dengan hanya menempatkan AC pada ruang tertentu sebesar 57\% atau dengan indikator cukup terlaksana.

\section{2) Aspek Penghematan dan Konservasi Air}


Yaitu upaya yang dilakukan dalam rangka penghematan penggunaan air, pemanfaatan dalam penggunaan air.Berdasarkan penelitian yang telah dilakukan berikut adalah hasil perilaku penerapan konsep Green-office pada aspek penghematan dan konservasi air dari sisi pegawai diperoleh skor 56\%. Pelaksanaan penerapan konsep green office gedung Bank Mandiri berdasarkan interval skor menunjukkan kriteria cukup terlaksana. Sedangkan pada sisi pelanggan diperoleh skor 53\% yang berdasarkan interval skor menunjukkan kriteria cukup terlaksana.

\section{3) Aspek Pengelolaan Limbah Kantor}

Yaitu implementasi terhadap keberadaan tempat sampah baik di dalam ataupun diluar gedung, ketersediaan tempat sampah yang terpilah agar sampah dapat di daur ulang sesuai dengan kriterianya, dan kebersihan lingkungan gedung Bank Mandiri. Berdasarkan hasil penelitian diperoleh skor sebesar 65\% dari sisi perilaku pegawai yang menunjukkan kriteria cukup terlaksana sedangkan dari sisi pelanggan diperoleh skor $69 \%$ berdasarkan interval skor menjukkan kriteria sudah terlaksana.

\section{4) Aspek Penghijauan}

Yaitu ketersediaan taman untuk penghijauan baik didalam ataupun diluar gedung. Berdasarkan hasil penerapan pada aspek penghijauan ditinjau dari sisi perilaku pegawai, maka total skor penerapan konsep green office dari aspek penghijauan di gedung Bank Mandiri sebesar $66 \%$. Pelaksanaan penerapan konsep green office gedung Bank Mandiri berdasarkan interval skor menunjukkan kriteria cukup terlaksana. Sedangkan total skor penerapan konsep green office dari aspek penghijauan di gedung Bank Mandiri sebesar 70\% ditinjau dari sisi pelanggan yang menunjukkan kriteria sudah terlaksana.

\section{5) Aspek Upaya lainnya}

Yaitu upaya lain yang dilakukan selain kriteria sebelumnya yang mendukung penerapan konsep green office seperti adanya sosialisasi ataupun himbauan untuk tidak merokok di ruang publik seperti ruang kerja, penggunaan kertas doublesida untuk membuat konsep-konsep laporan, mengutamakan prinsip paper less salah satunya dengan memanfaatkan sarana email sebagai media pengiriman data, serta pelaksanaan pentingnya implementasi prinsip green office untuk karyawan.

\section{SIMPULAN DAN SARAN}

\section{Simpulan}

\section{PT Mandiri (Persero) Tbk., Surakarta Jawa Tengah}

Perwujudan kantor ramah lingkungan sudah diterapkan di PT Bank Mandiri (Persero) Tbk., Surakarta Jawa Tengah.Implementasi konsep green office yang sudah diujikan pada pelanggan dan pegawai gedung Bank Mandiri yaitu aspek penghematan listrik, aspek penghematan dan konservasi air, aspek pengelolaan limbah kantor, aspek penghijauan dan aspek upaya lainnya diperoleh persebaran tingkat adalah sebagai berikut penghematan listrik $(52,5 \%)$, penghematan dan konservasi air $(54,5 \%)$, pengelolaan sampah kantor $(67 \%)$, penghijauan $(68 \%)$, dan upaya lainnya (52\%). Implementasi konsep Green office pada gedung Bank Mandiri hasilnya mengerucut pada skor 58,8\% yang menunjukkan bahwa penerapan konsep Green office di gedung Bank Mandiri sudah cukup terlaksana.

\section{Saran}

\section{PT Mandiri (Persero) Tbk., Surakarta Jawa Tengah}

Saran dari hasil penelitian ini yaitu :

a) Berkenaan dengan penghematan energi listrik maka perlu dilakukan beberapa upaya seperti penyetelan mode stand by pada setiap komputer, mematikan listrik di ruangan pada saat jam istirahat.

b) Mengurangi pemakaian lampu dengan memanfaatkan energi dari cahaya matahari.

c) Penggunaan lampu hemat energi agar tidak menghabiskan banyak biaya untuk listrik dan penggantian lampu yang rusak.

d) Penghematan energi listrik khususnya AC sebaiknya dilakukan pembatasan jam aktivasi. Sistem pendingin ruangan dilakukan penonaktifan saat jam tidak produktif pada ruang kantor 
e) Diperlukan pemasangan sistem tangkapan air hujan sehingga dapat melakukan daur ulang air untuk menyiram tanaman atau menyiram toilet. Peralatan sanitasi yang dipakai merupakan peralatan yang mampu menghemat seperti penggunaan toilet flush hemat air.

f) Penghematan air dapat dilakukan dengan cara recycle. Penggunaan yang dapat diterapkan antara lain menggunakan air wudhu untuk mencuci mobil, menyiram taman dengan menggunakan teknologi filter, penggantian toilet dan sistem perpipaan (Pemantauan Pencemaran Lingkungan, 2009).

g) Penyediaan fasilitas tempat sampah yang memadai dan terdistribusi secara merata berdasarkan jenisnya disertai dengan pelabelan yang jelas, sosialisasi yang baik serta dilakukan pengawasan yang kontinyu. Selain itu juga disediakan tempat sampah khusus untuk kertas (paper bin) di setiap sumber penghasilnya seperti dekat mesin fotokopi dan printer

h) Menyediakan beberapa poster atau himbauan yang ditempelkan pada dinding di sudut-sudut tertentu yang menerangkan tata cara penghematan energi listrik dan air.

i) Menambah penghijauan di dalam ruangan gedung.

Memanfaatkan kembali limbah kantor.

j) Melakukan sosialisasi penerapan green office pada pegawai serta pengunjung (nasabah) gedung Bank Mandiri.

\section{DAFTAR PUSTAKA}

Amelia, Ivone, Rizky Sarwono, Ainul, Hayat. Konsep Green-Office Dalam Rangka Mewujudkan Perkantoran Ramah Lingkungan (Studi Pada Kantor Walikota Probolinggo). Jurnal Administrasi Publik (JAP), Vol. 2, No. 3, Hal. 478-484

Detik Kamis, 27 Apr 2017 14:14 WIB. (30 November 2019). Citing Internet sources URL. https://finance.detik.com/berita-ekonomi-bisnis/d-3485474/ada-398-juta-perusahaan-baru-di-ri-dalam10-tahun-terakhir

Biro Pusat Statistik (BPS) 2018. (30 November 2019). Citing Internet sources URL https://www.bps.go.id/linkTableDinamis/view/id/896

Biro Pusat Statistik (BPS) Citing Internet sources URL https://se2016.bps.go.id/umkumb/files/brs/BRS_hasillisting.pdf.

Datuak Tjumano, On: July 3, $2018 \quad$ Citing Internet sources URL https://jurnalintelijen.net/2018/07/03/kerusakan-lingkungan-hidup-di-indonesia/

Fitriani, Dian \& Sri Astuti, Penerapan Green OfficePada Bagian Rumah Tangga Kementerian Kesehatan Republik Indonesia. Jurnal Utilitas Vol. 2 No. 1 April 2016. ISSN: 2442- 224x

Maninriang, Armin. 2013. Skripsi: Gambaran Sistem Manajemen Lingkungan ISO 14001 Pada PT PLN Sulselrabar (Persero) Sektor Tello Makassar Tahun 2013. Makasar: Universitas Alauddin.

Mufidah, Ida, Umarul. Analisis Komparatif Manajemen Strategis Green Office Antara Badan Pengembangan Dan Pemberdayaan Sdm Kesehatan (Bppsdmk) Dan Sekretariat Jenderal (Sekjen) Di Lingkungan Kemenkes RI. PLPB: Pendidikan Lingkungan dan Pembangunan Berkelanjutan. Volume XVIII Nomor 01 Maret 2017 ISSN 1411-1829

Citha Setia Rukmita, Citha, dkk. Implementasi Konsep Green Office Berdasarkan Perilaku Pengguna Di Lingkungan Gedung. Seminar Nasional Pendidikan Biologi dan Saintek 2018.

Rahmawati, Noor, Indah. Geliat Green Office di Indonesia. Jurnal Ekonomi Pem bangunan Vol. 3, No. 2 (2017) 124-136

Sukardi2013 ,Metodologi Penelitian Pendidikan Kompetensi dan Praktiknya. Jakarta : PT Bumi Aksara

Sujarweni ,V. Wiratna., . 2014. Metodologi Penelitian. Yogyakarta : Pustaka Baru Perss

\section{Undang-undang:}

Anonymous. Undang-Undang Nomor 32 Tahun 2009 tentang Perlindungan dan Pengelolaan Lingkungan hidup 